\title{
DIGITALCOMMONS
}

—@WAYNESTATE-

Wayne State University

$10-1-2004$

\section{Psychodynamic Perspectives on Relationship: Implications of New Findings From Human Attachment and the Neurosciences for Social Work Education}

Jerrold R. Brandell

Wayne State University, aa4537@wayne.edu

Shoshana Ringel

University of Maryland - Baltimore

\section{Recommended Citation}

Brandell, J. R., \& Ringel, S. (2004). Psychodynamic perspectives on relationship: implications of new findings from human attachment and the neurosciences for social work education. Families in Society, 85(4), 549-556.

Available at: http://digitalcommons.wayne.edu/soc_work_pubs/7 


\title{
Psychodynamic Perspectives on Relationship: Implications of New Findings From Human Attachment and the Neurosciences for Social Work Education
}

\author{
Jerrold R. Brandell \& Shoshana Ringel
}

\begin{abstract}
In this article, the historical significance of the therapeutic relationship in social casework theory and practice is discussed and elaborated on in relation to contemporary psychodynamic theories and constructs, such as the therapeutic alliance, the holding relationship, and selfobject theory. The significant contributions of investigators in such diverse fields as infant attachment, neurobiology, and feminist theory are then discussed in relation to these psychoanalytic ideas. Based in part upon recent research being conducted in such fields, a more central role is proposed for psychodynamic conceptions of relationship in the education of social work clinicians.
\end{abstract}

W ith the current emphasis in social work practice education on behavioral techniques, evidencebased practice, and measurable outcomes, more subtle and elusive domains such as the therapeutic relationship and the therapeutic process, the use of self, and an appreciation for the unique character of each client may be overlooked. This was not always so, however. Historically, social work emphasized the humanizing qualities of relationship as central to the encounter between caseworkers and clients, a motif that echoes throughout the contributions of social casework theorists (Biestek, 1957; Garrett, 1958; Hamilton, 1937; Hollis, 1965; Perlman, 1979; Richmond, 1917; Robinson, 1930; Strean, 1978). The psychodynamic models in which casework took root have, from the very beginning, emphasized relational dynamics and process as central concerns in treatment.
More recently it has been shown that the early relationships between infants and caregivers have a pivotal influence on later personality and relational style. A substantial body of research on neurobiological development and on infant attachment patterns suggests that relational templates formed in infancy and early childhood exert a powerful impact on the development of cognitive, physiological and affective structures (Ainsworth, Blehar, Water, \& Wall, 1978; Beebe \& Lachmann, 2002; LeDoux, 1996; Schore, 1997; Stern, 1985; Tronick, 1989). This rich body of research now provides a strong scientific underpinning for the centrality of relationship not just with respect to human development, but also as it has been conceived in various feminist and relational paradigms that have influenced the direction of contemporary psychodynamic practice. 


\section{Historical Perspectives in Social Work and Psychodynamic Theory}

Although relationship has long been emphasized in the social casework literature, it was originally conceived in a nondynamic way. Mary Richmond (1899), writing over 100 years ago, noted that

friendly visiting means intimate and continuous knowledge of and sympathy with a poor family's joys, sorrows, opinions, feelings, and entire outlook upon life. The visitor that has this is unlikely to blunder about relief or any detail; without it he is almost certain, in any charitable relations with members of the family, to blunder seriously. (p. 180)

In this early view, one that is framed in the language of the charity organization movement, relationship is not thought of as a dynamic, interactive process, but as something akin to a friendship. As a matter of fact, it wasn't until 1930 that the term "relationship" was finally adopted as a way of characterizing the encounter between the worker and client (Biestek, 1957; Robinson, 1930). Although other terms such as empathy and rapport were subsequently introduced to enhance this early characterization, these conceptions of relationship lacked dimension. When, in the late 1920s, the psychoanalytic concept of transference was first used in the social casework lexicon, thereby adding considerable complexity to the simple formula originally provided by Richmond, it may have furnished additional impetus to efforts to define the nature of the casework relationship. ${ }^{1}$

In the late 1950s, Felix Biestek introduced his now-classic volume, The Casework Relationship (1957). In this book, he outlined seven principles of relationship distilled from a comprehensive analysis of the extant casework literature. These consisted of individualization, purposeful expression of feelings, controlled emotional environment, acceptance, nonjudgmental attitude, client self-determination, and confidentiality (Biestek, 1957). One might argue that these principles are in basic synchrony not only with important psychoanalytic concepts emerging in the mid 1950s regarding nontransferential aspects of the analytic relationship, but that they also presage the work of Carl Rogers and his colleagues on the "facilitative conditions" for effective psychotherapy. Biestek's emphasis on a professional relationship emphasizing the creation of an interpersonal climate in which clients are encouraged to express their feelings openly, and workers respond with nonjudg- mental acceptance, also calls to mind the object-relations notion of the "holding environment."

Though originally used to describe the facilitative maternal environment through which the good enough mother is able to offer her infant emotional security, which ultimately affords him or her protection against the inevitable failures in maternal attentiveness or empathy, this concept also possesses a unique currency in the casework treatment situation. In the broad context of social services, holding may be defined to include the provision of material goods, such as food, housing, or financial assistance; the provision of family preservation programs or respite care; or even the removal of children who have been subject to abuse or neglect (Applegate \& Bonovitz, 1995). In the clinical milieu, the good enough parent is, of course, the therapist, the holding metaphorical rather than literal. What elements, however, are associated with such therapeutic holding?

Foremost among these would be the creation of a safe emotional environment, in which the client can feel relative comfort and security in disclosing the details of her personal life. Oftentimes, such a safe environment is possible only through therapeutic containment, whereby elements of the client's rudimentary identity, as well as rage, violent projections or fantasies, and other internally arising dangers are absorbed and therapeutically metabolized by the clinician (Bion, 1962, Klein, 1974; Meissner, 1996; Ogden, 1982). The therapeutic effect of such containment is to assure the client that the therapist cannot be destroyed and that she or he is a good container for such dangerous thoughts, wishes, or impulses, thus furnishing the client with a "safe context for emotional discharge" (Meissner, 1996, p. 20). The safety of the therapeutic environment may also be enhanced or managed through various external structures (e.g., institutional rules or psychotropic medications) that function to diminish frightening thoughts or impulses. The therapist's genuine interest in and concern for the client, her ability to listen attentively to the client's story as it unfolds, and reasonable efforts to remain affectively attuned and empathically

\footnotetext{
1 An even greater motive was the gradual movement toward professionalization within social work, which required greater conceptual clarity as well as the substitution of a new scientific terminology for the experience-near language of casework pioneers such as Mary Richmond.

2 Empathy, positive regard, and congruence constituted the original facilitative conditions identified in Rogers' seminal research (Rogers, 1957), although this list was later amended to include nonpossessive warmth and genuineness (Truax \& Carkhuff, 1967).
} 
resonant are clearly also of importance. Although his remarks were specific to the analytic relationship, Winnicott's comments about holding seem readily applicable to the casework relationship. Writing over 40 years ago, he observed, "The analyst is holding the patient (emphasis in the original), and this often takes the form of conveying in words at the appropriate moment something that shows that the analyst knows and understands the deepest anxiety that is being experienced, or that is waiting to be experienced" (Winnicott, 1963, p. 240).

Meissner, a psychoanalyst, observed that the Winnicottian holding environment helped to explain how therapeutic rapport might be possible with psychoanalytic patients incapable of developing a transference neurosis or of forming a therapeutic alliance. The concept of a holding environment permitted a shift of focus from more classical notions about the overriding importance of "mutative interpretation to the affective relatedness between analyst and patient, providing a safe context for the analytic process" (Meissner, 1996, p. 19). In particular, it helped to illuminate the nature of the therapeutic action in more primitively functioning, personality disordered clients who could not immediately make use of conventional interpretive work. Meissner (1996) suggested, "Holding thus provides an illusion of safety and protection from dangers both within and without" (p. 19).

At times, special measures may be necessary to create and maintain the illusory holding environment. Goldstein (2001) suggested that the use of transitional objects and other transitional phenomena may assist certain clients with impaired object-relational capacities to preserve an emotional connection with the therapist that would otherwise be impossible to sustain between appointments. At times, these may consist of the therapist's telephone number or an item associated with the therapist or the office in which she or he works, the therapist's e-mail address, and so forth. Although such practices were at one time dismissed as unconventional treatment parameters by the psychoanalytic establishment, their value in clinical work with very disturbed clients is now well established. However, therapeutic holding cannot be easily reduced to specific technical parameters or formulas, leading Moore and Fine (1990) to conceive of it as a "non-specific supportive continuity," established in part through "the regularity of visits, rituals of coming and going, the underlying empathy, the steadiness of voice, and the very continuity of the objects, spaces, and textures" of the office or meeting space (p. 206). ${ }^{3}$

It is through the combined effect of such experiences of being held in treatment that clients' fears of the annihilation of both self and object can be relieved (Klein, 1974), and a greater capacity to tolerate frustrations caused by the unavoidable discontinuities in the process of therapy is acquired. Such discontinuities are, of course, as often as not due to breaches in the treatment relationship itself, which may in turn be linked to technical errors or misattunement on the therapist's part.

\section{The Therapeutic Alliance}

The concept of the therapeutic alliance, whose origins can be traced to Freud and his disciple, Richard Sterba, was later elaborated on by a number of psychoanalysts and social work theorists, and although remaining a controversial idea in some quarters, it gradually acquired a position of respectability (Meissner, 1996). It has been variously defined, although most definitions have emphasized three factors:

1. The contractual arrangements through which the logistics of treatment are specified (e.g., scheduling, fee setting and payments, confidentiality, etc.)

2. Consensus as to how therapist and client will work together and with what objectives in mind

3. An understanding and acceptance of the specific roles and responsibilities assigned to each

Social work practice arose from a tradition in which the idea of alliance and alliance building is almost inextricable from conceptions of treatment. Paradoxically, because this idea is so embedded, the result has been considerable development devoted to its molecular components, such as contracting, treatment objectives, worker and client roles, and so forth, although somewhat less attention has been given to the more encompassing concept of alliance. For psychoanalysts, the development of a theory emphasizing the therapeutic alliance appears to have been a belated development, only gaining real momentum in the 1950s and 1960s with the work of such authors as Zetzel (1956, 1970), Stone (1961), and Greenson $(1965,1967)$. There are undoubtedly several reasons for this, not the least of which is the superordinate role and strength psychoanalysts had historically attributed to the unconscious in mental life and psychopathology, in general, and in the psychoanalytic treatment process, more specifically. That important aspects of the treatment relationship might be influenced or shaped by forces residing closer to consciousness would have been incompatible with this early classical view of the unconscious. A related difficulty is that psychoanalysis was originally an id psychology in which the principle of psychic determinism was an a priori assumption, and the concept of alliance, in which an individual's self-determination is a central element, appears to be at least partly at variance with this principle. Yet another factor may have been the gradual transformation from a predominantly classical vision of the analytic treatment process, often referred to as a one-person psychology, to a greater range of clinical and theoretical perspectives in which the human dimension was elevated (e.g., Fromm-Reichmann, 1950; Sullivan, 1953). Finally, the disentangling of the notion of alliance

\footnotetext{
3 Handling is a specific term sometimes used to denote the structural arrangements that contribute to the maintenance of a therapeutic holding environment. Agency policies and procedures, the setting of fees, cancellation policies, appointment times, and so forth constitute such "containing boundaries of clinical work" (Applegate \& Bonovitz, 1995, pp. 112-113).
} 
from that of transference has proven to be a formidable task for psychodynamic theorists.

Meissner, a creative scholar who has done a great deal to restimulate contemporary psychoanalytic interest in the therapeutic alliance, has developed a multidimensional model of the alliance (Meissner, 1992, 1996). Central to his thinking is the idea that the therapeutic alliance resides not only in the client, but rather involves an interactive process to which both participants contribute. Although he agrees that there is a complex commingling of the transference, the real relationship, and the therapeutic alliance in the crucible of therapeutic process, he also believes these are distinguishable if not substantially discrete entities.

In his model of the therapeutic alliance, Meissner included not only such features as mutual empathic attunement, the therapeutic contract or framework, and mutual responsibilities within the treatment relationship, he also identified such qualitative dimensions as freedom, trust, autonomy, initiative, and ethics as operational factors. Meissner's model of the therapeutic alliance is important chiefly because it places the alliance at the center of the therapeutic effort. He believes it is considerably more complex than the earlier formulations of such writers as Sterba, Zetzel, and Greenson, whose focus was principally on the notion of collaboration and rational cooperation. Acknowledging the complex nature of the alliance, which is in appreciable measure a product of the interpenetration of the dimensions described above, Meissner (1992) concluded that the therapeutic alliance is "vital to the beneficial outcome of any therapeutic process, analytic or not" (p. 1084).

\section{Kohut's Self Psychology}

Psychoanalytic self psychology, acknowledged even by its critics as one of the most important new theoretical developments in psychoanalysis during the last 30 years, has contributed a great deal to our understanding of human development, developmental derailments, and other forms of psychopathology. Kohut's formulations, some would argue, have also changed our understanding of what is curative in the therapeutic process. Because self psychological ideas regarding the nature of the relationship in general and of the transference relationship in particular are sufficiently unique to set this theoretical system apart from other psychoanalytic frameworks, we briefly summarize these ideas.

Kohut coined the term selfobject to refer to a particular kind of object relationship in which the object is actually experienced as an extension of the self, without psychological differentiation. He observed that

the expected control over such [selfobjects].... is then closer to the concept of control which a grownup expects to have over his own body and mind than to the .... control which he expects to have over others. (Kohut, 1971, pp. 26-27)
Kohut believed that infants are born into an interpersonal milieu that optimally provides them with three distinctly different though equally necessary kinds of selfobject experiences. One kind of experience calls for mirroring selfobjects, "who respond to and confirm the child's innate sense of vigor, greatness and perfection" (Kohut \& Wolf, 1978, p. 414). A second variety of selfobject experience requires the powerful and reassuring presence of caregivers "to whom the child can look up and with whom he can merge as an image of calmness, infallibility, and omnipotence" (ibid). Kohut later introduced a third selfobject realm, referred to as alter ego or partnering selfobjects. This third variety provides a range of experiences through which children acquire a sense of belonging and of essential alikeness within a community of others.

Self psychologists believe that the therapist's basic attitude of concern and compassionate acceptance and his or her promotion of an ambience of emotional vitality and responsiveness are necessary to bring about the therapeutic remobilization of various archaic selfobject needs, considered a sine qua non for meaningful psychotherapy. This therapeutic stance has often been presented in stark contrast to the "detached, cold, abstemious, surgeonlike demeanor" (Leider, 1996, p. 155) attributed to Freud and to his rendering of classical psychoanalytic technique (e.g., Freud, 1912).

The interpretative process in self psychology consists of two basic phases: a phase of understanding, superceded by a phase of explanation and interpretation. Both of these phases are deemed essential to the therapeutic process (Kohut, 1984). With the unfolding of the therapeutic process and the establishment of a selfobject transference, the client unconsciously perceives the therapist as fulfilling various selfobject needs. It is the client's dawning perception that the therapist has somehow failed to satisfy these selfobject needs (an unavoidable eventuality) that leads to fragmentation, archaic affect states, and other sequelae of misattunement. Such therapeutic breaches, however, are not only unavoidable in the view of self psychology, but necessary for further psychological growth and structural repair (Kohut, 1977; Leider, 1996; Wolf, 1988).

The phase of understanding commences with the therapist's recognition of the empathic rupture or breach, which the therapist then conveys to the client. Such therapeutic communications, accompanied by the therapist's attempt to reconstruct and characterize the events leading to the disruption, serve to reestablish psychological homeostasis (Kohut, 1984). This makes possible explanation in which the significance of the therapeutic breach is recast in dynamic-genetic terms, permitting the client and therapist to reconstruct the circumstances of childhood in which parental selfobjects were chronically unavailable, "analogous disruptions occurred, and the self was permanently injured" (Leider, 1996, p. 157).

Psychodynamic theories and treatment principles have been marginalized in social work practice education for better than a generation, although current attachment research, infant studies, feminist theories, postmodernism, and neurobiological findings have led to a resurgence of interest in these ideas (LeDoux, 1996; Montgomery, 2002; Schore, 1997, 
2003a, 2003b). In the remainder of this article, we will examine the significance of this recent research, whether it lends support to some of the historical and contemporary ideas about the treatment relationship that we have summarized, and how it may enhance social work professionals' understanding of relational phenomena in a clinical context. We will conclude the article with a brief discussion of the relevance of these theories and scientific findings to social work practice and education.

\section{Early Relationships and Attachment Research}

That early relationships are central in their effects on later development has been empirically demonstrated through a substantial body of research on infants' attachment patterns (Ainsworth et al., 1978; Beebe \& Lachmann, 2002; Fonagy, 1999; Lyons-Ruth, 1999; Schore, 1997; Stern, 1985; Tronick, 1989). Ainsworth (Ainsworth et al., 1978) and Bowlby (1988) were the first to show that relational dynamics between infants and caregivers exert profound effects on the personality structure of children. In later studies, Main (2000) found that these early attachment templates could become stable adult personality styles. More recently, however, researchers found that neurobiological structures are profoundly
Students can learn how, through the therapeutic relationship, clients may be taught to self-regulate and work through old, problematic relational patterns. more primitive limbic system and the amygdala, which is responsible for fear responses (LeDoux, 1996). Emotional responsiveness by caregivers, for example, was shown to stimulate more rapid firing of neurons in the orbitofrontal neurons, causing greater brain stimulation (Schore, 1997). The brain's orbitofrontal cortex is differentiated into right and left hemispheres; the right brain, which matures earlier, regulates affective experience, whereas the left brain is the center of verbal and analytic functions. Because the infant's cognitive capacities are not yet fully developed in terms of language, memory, and perception, experiences are encoded through a variety of nonverbal signals such as gazing, facial expression, touch, voice tone, and so forth, into the limbic system and the amygdala. It is only when language and cognition are more developed that these experiences can be articulated. Although psychotherapy seems to start as a right-brain to right-brain experience through unconscious and nonverbal communication processes, it then progresses into leftbrain experience when nonverbal experiences are translated into language and insight.

These scientific data provide an explanation for theoretical concepts and practice principles that have long been emphasized in psychodynamic treatment. These include an emphasis on a dynamic unconscious, transference and countertransference paradigms, the process of working through, influenced by the earliest attachment patterns between infants and caregivers (LeDoux, 1996; Schore, 1997; Tronick, 1989). Thus, interactions between infants and caregivers can form relatively stable neuronal structures in the child, becoming the basis for emotional interactions between self and others throughout life (Applegate, 2004). Although one or two interactions may not leave a lasting impact, repetitive patterns can profoundly alter the brain structure and have a lasting impact on physical health, cognitive development, and affective response patterns (McEwen, 2002).

\section{Neurobiological Structures and Psychological Development}

Neurobiology and brain imaging techniques (e.g., a positron-emission tomography or PET scan) have shown that early relational patterns between the child and the caregiver can become permanent neurological templates, especially during the child's first few years, during which brain plasticity is the greatest. However, brain development can also occur in later adulthood through new experiences and relationships, including, for example, the therapeutic relationship. The brain's executive center, the orbitofrontal cortex, is responsible for modulating emotion and behavior that originate in the and insight. It is only in the last few years, however, that neurobiological research has become sufficiently advanced to provide the scientific underpinning to these earlier psychodynamic concepts. In the last couple of years, these scientific advances have found a receptive audience among social work clinicians and academics, as demonstrated by very recent publications in several social work journals in which the authors apply neurobiological findings to social work education and practice (e.g., Applegate, 2004; Montgomery, 2002; Shapiro \& Applegate, 2000).

\section{Psychodynamic Theory and Neurobiological Findings}

Psychodynamic theory, with its emphasis on underlying meaning, unconscious processes, relational dynamics, and insight, appears to be consistent with recent neurobiological findings. Psychodynamic models aim at deeper, unconscious, and often preverbal affects and experiences that constitute the infrastructure of the personality. In their studies of infants, Fonagy and Target (1998) found a direct link between the more primitive parts of the brain (the limbic system, which stores emotions) and the cortical system in which the cognitive structure develops. Fonagy and Target called this 
connection mentalization-the ability to transfer emotional and nonverbal body experiences into a cognitive framework, that is, verbal memory, self-reflection, and insight. This concept is congruent with psychodynamic therapy, which emphasizes the development of insight as an important goal of the treatment. Self psychology, a theory that emphasizes the therapist's regulatory role in regard to the clinical reactivation of the client's selfobject needs for attuned mirroring, partnering, and empathy, can also be understood in relation to neurobiological processes. For example, it was shown that mutual gazing in the mother-infant dyad triggered high levels of endogenous opiates in children's developing brains. The effects of treatment and of the therapist's activities may actually serve to stimulate and sustain the process of creating new and potentially more adaptive internalized patterns for object relations. One illustration of the biological base of internalized representation was revealed when PET scans were taken of subjects who experienced the loss of significant others. These scans showed an increased blood flow in the orbitofrontal areas, indicating that relational emotional experiences have a corresponding neurological activity (Schore, 1997). Such evidence lends increasing support to the idea that the therapist's regulatory functions may help clients increase neuronal activities, develop new neurological structures, and ultimately internalize appropriate self-regulatory abilities.

\section{Feminist Theories and Neurobiological Developments}

Feminist theories that emphasize mutuality, empathy, and intersubjectivity as central qualities in women's development and in feminist practice (Benjamin, 1995; Jordan, Kaplan, Miller, Stiver, \& Surrey, 1991) also find a new relevance in current neurobiological findings. These theories, based on work conducted at the Stone Center and originally inspired by Miller's (1976) pioneering volume on female psychology and Gilligan's (1982) early studies of the unique development of adolescent girls, led clinicians to investigate such qualities as relationality, empathy, and a sense of self contingent on interactions with others-qualities that women are socialized to express. Benjamin (1995) elaborated on the developmental importance of intersubjectivity, or the mutual affective contributions between child and caregiver (and by implication client and clinician), and viewed them as furnishing an essential basis for psychological maturity. As previously discussed, these feminist paradigms were supported by attachment research and by recent neurobiological findings. For example, distinctive gender differences were found in the brain structures of men and women. In women, both frontal lobes of the brain were found to be sensitive to feeling states, which suggested the possibility that women may be capable of higher levels of empathy. In men, however, only the right hemisphere was found to be sensitized to emotional input (Schore, 1997). When such findings are juxtaposed with infant studies and current attachment research citing the long-term effects of early infant-caregiver interactions on brain structure, personality style, and adult relationships, they appear to strengthen the long-held feminist theoretical position that emphasizes intersubjectivity as a central organizer for development throughout the life cycle.

\section{Implications for Clinical Practice}

The emphasis on relational aspects of the therapeutic process coincides with new developments in psychodynamic theories, such as intersubjectivity theory (Stolorow, Atwood, \& Brandchaft, 1997) and relational theory (Mitchell, 1997). Even some current cognitive-behavioral models have adopted the therapeutic relationship as a central foundation of the treatment, a recent example of which is Linehan's (1993) application of dialectical behavioral therapy to the treatment of suicidal patients, in which the therapeutic relationship is emphasized as the foundation for all other cognitive and behavioral techniques. Contemporary relational and intersubjective approaches emphasize the nature of the therapeutic relationship from a two-person, rather than a one-person psychology, where the interpersonal dynamics of the treatment are seen as central domains of the clinical investigation. These explorations include the mutual contributions each partner in the clinical endeavor makes through conscious and unconscious means, including nonverbal processes. Consequently, the investigation of clients' familial history, defense structures, and relational skills-processes that are significantly mediated through the therapeutic relationship_can provide a rich source of information and mutual insights for both client and clinician.

\section{Implications for Social Work Practice Education}

These new scientific findings can now help bridge practice paradigms and empirical research. Findings from attachment and neurobiological research, for example, can reinforce clinical practice content by helping students understand how clients may internalize aspects of their caregivers and of the therapeutic encounter, and thereby develop new and more adaptive relational working models. Students can learn how, through the therapeutic relationship, clients may be taught to self-regulate and work through old, problematic relational patterns. By emphasizing the value of an intersubjective inquiry between client and clinician, students can learn to become more aware of biases and stereotypes that may color their understanding of clients' narratives. Finally, they can learn to appreciate the mutual influence of client and clinician on one another. In psychodynamic treatment, the relationship between client and clinician is the central object of attention. Both verbal and nonverbal communications become encoded in the brain, and only through the development of insight can sensory and nonverbal emotional experiences ultimately be understood and expressed by clients.

The integration of attachment and neurobiological research with psychodynamic practice can also be applied to specific 
social work areas of practice, such as child welfare and domestic violence. Clearly, early relational disruptions that may have resulted in cognitive and affective delays in development are important components of these systemic problems. The biological, cognitive, and affective impact of cumulative stress that may result from a client's socioeconomic, race, ethnic, gender, sexual orientation, and disability status might also be better understood and treated by integrating these scientific findings and treatment paradigms. Finally, specific diagnostic criteria in the Diagnostic and Statistical Manual of Mental Disorders (American Psychiatric Association, 1994), such as mood, anxiety, and personality disorders, can be seen more multidimensionally by utilizing neuroscience and attachment perspectives.

Therefore, a solid psychodynamic knowledge base supported by the understanding of neurobiological structures and processes may serve as an important asset for social work students with a broad range of clients and across diverse settings. Moreover, neurobiological and genetic aspects of development, behavior, and affect can now be incorporated into the traditional framework of biopsychosocial assessment. Collectively, these areas represent important considerations in, among many possible examples, learning disabilities, the evaluation of response to trauma, and the understanding of disorders of attachment.

\section{Conclusion}

In this article, we have elaborated on the historical significance of the therapeutic relationship in casework theory and practice, in contemporary psychodynamic theories, and through current empirical research. We have also focused specifically on how social work professionals' conception of relationship, as both a developmental process and as the central organizing feature of any treatment endeavor, can be meaningfully augmented through the integration of new knowledge derived from two principal bodies of research. These two fields, human attachment and the neurosciences, have already profoundly shaped the understanding of the course of early development and of the relationship between brain and environment. They also lend credibility to some long-held as well as more recent psychodynamic, feminist, postmodernist, and intersubjective theoretical assumptions about the nature of the therapeutic process. Perhaps most significantly, these recent research findings underscore the importance of psychodynamic conceptions of the treatment relationship, ideas that have gradually been supplanted by other models of social work treatment in which relationship may be conceived of with either less emphasis or complexity. On the basis of the conceptual literature and empirical findings presented here, we submit that the psychodynamic perspective on relationship can be legitimately assigned a more central role in social work education and indeed, that it offers a unique perspective consonant with emerging knowledge in both psychobiology and human development.

\section{References}

Ainsworth, M. D., Blehar, M. C., Water, E., \& Wall, S. (1978). Patterns of attachment: A psychological study of the strange situation. Hillsdale, NJ: Erlbaum.

American Psychiatric Association. (1994). Diagnostic and statistical manual of mental disorders (4th ed.). Washington, DC: Author.

Applegate, J. (2004). Returning psychoanalytic theory to social work education. Psychoanalytic Social Work, 11, 23-36.

Applegate, J., \& Bonovitz, J. (1995). The facilitating partnership: A Winnicottian approach for social workers and other helping professionals. Northvale, NJ: Aronson.

Beebe, B., \& Lachmann, F. (2002). Infant research and adult treatment. Northvale, NJ: Analytic Press.

Benjamin, J. (1995). Like subjects love objects. New Haven, CT: Yale University Press.

Biestek, F. (1957). The casework relationship. Chicago: Loyola University Press. Bion, W. (1962). Learning from experience. New York: Basic Books.

Fonagy, P. (1999). Points of contact and divergence between psychoanalytic and attachment theories: Is psychoanalytic theory truly different? Psychoanalytic Inquiry, 19, 448-480.

Fonagy, P., \& Target, M. (1998). Mentalization and the changing aims of child psychoanalysis. Psychoanalytic Dialogues, 8, 87-114.

Freud, S. (1912). The dynamics of transference. The standard edition of the complete psychological works of Sigmund Freud, 12, 99-108. Trans. J. Strachey, London: Hogarth Press, 1973.

Fromm-Reichmann, F. (1950). Principles of intensive psychotherapy. Chicago: University of Chicago Press.

Garrett, A. (1958). The worker-client relationship. In H. Parad (Ed.), Ego psychology and dynamic casework (pp. 53-72). New York: Family Service Association of America.

Gilligan, C. (1982). In a different voice. Cambridge, MA: Harvard University Press.

Goldstein, E. (2001). Object relations theory and self psychology in social work practice. New York: Free Press.

Greenson, R. (1965). The working alliance and the transference neurosis. Psychoanalytic Quarterly, 343, 155-181.

Greenson, R. (1967). The technique and practice of psychoanalysis. New York: International Universities Press.

Hamilton, G. (1937). Basic concepts in social casework. The Family, 18, 147-156.

Hollis, F. (1965). Casework: A psychosocial therapy. New York: Random House.

Jordan, J., Kaplan, A., Miller, J. B., Stiver, I., \& Surrey, J. (1991). Women's growth in connection. New York: Guilford.

Klein, H. (1974). Transference and defense in manic states. International Journal of Psychoanalysis, 55, 261-268.

Kohut, H. (1971). Analysis of the self. New York: International Universities Press.

Kohut, H. (1977). Restoration of the self. New York: International Universities Press.

Kohut, H. (1984). How does analysis cure? Chicago: University of Chicago Press.

Kohut, H., \& Wolf, E. (1978). The disorders of the self and their treatment: An outline. International Journal of Psychoanalysis, 59, 413-425.

LeDoux, J. (1996). The emotional brain: The mysterious underpinnings of emotional life. New York: Simon \& Schuster.

Leider, R. (1996). The psychology of the self. In E. Nersessian \& R. Kopff (Eds.), Textbook of psychoanalysis (pp. 127-164). Washington, DC: American Psychiatric Press.

Linehan, M. (1993). Cognitive-behavioral treatment of borderline personality disorder. New York: Guilford.

Lyons-Ruth, K. (1999). The two-person unconscious: Intersubjective dialogue, enactive relational representation, and the emergence of new forms of relational organization. Psychoanalytic Inquiry, 19, 576-617.

Main, M. (2000). Recent studies in attachment: Overview, with selected implications for clinical work. In S. Goldberg, R. Muir, \& J. Kerr (Eds.), Attachment theory: Social, developmental, and clinical perspectives (pp. 407-474). Hillsdale, NJ: Analytic Press.

McEwen, B. (2002). The end of stress as we know it. Washington, DC: Dana Press.

Meissner, W. (1992). The concept of the therapeutic alliance. Journal of the American Psychoanalytic Association, 40, 1059-1087. 
Meissner, W. (1996). The therapeutic alliance. New Haven, CT: Yale University Press.

Miller, J. B. (1976). Toward a new psychology of women. Boston: Beacon.

Mitchell, S. (1997). Influence and autonomy in psychoanalysis. Northvale, NJ: Analytic Press.

Montgomery, A. (2002). Converging perspectives of dynamic theory and evolving neurobiological knowledge. Smith Studies in Social Work, 72, 177-196.

Moore, B., \& Fine, B. (1990). Psychoanalytic terms and concepts. New Haven, CT: Yale University Press.

Ogden, T. (1982). Projective identification and psychoanalytic technique. Northvale, NJ: Aronson.

Perlman, H. (1979). Relationship: The heart of helping people. Chicago: University of Chicago Press.

Richmond, M. (1899). Friendly visiting among the poor. New York: Macmillan.

Richmond, M. (1917). Social diagnosis. New York: Russell Sage Foundation.

Robinson, V. (1930). A changing psychology in social casework. Chapel Hill: University of North Carolina Press.

Rogers, C. (1957). The necessary and sufficient conditions of therapeutic personality change. Journal of Consulting Psychology, 22, 95-103.

Schore, A. (1997). Interdisciplinary developmental research as a source of clinical models. In M. Moskowitz, C. Monk, C. Kaye, \& S. Ellman (Eds.), The neurobiological and developmental basis for psychotherapeutic intervention (pp. 1-72). Northvale, NJ: Aronson.

Schore, A. (2003a). Affect dysregulation and disorders of the self. New York: Norton.

Schore, A. (2003b). Affect regulation and the repair of the self. New York: Norton.

Shapiro, J., \& Applegate, J. (2000). Cognitive neuroscience, neurobiology and affect regulation: Implications for clinical social work. Clinical Social Work Journal, 28, 9-21.

Stern, D. (1985). The interpersonal world of the infant. New York: Basic Books.

Stolorow, R., Atwood, G., \& Brandchaft, B. (1997). The intersubjective perspective. Northvale, NJ: Aronson.

Stone, L. (1961). The psychoanalytic situation. New York: International Universities Press.
Strean, H. (1978). Clinical social work: Theory and practice. New York: Free Press.

Sullivan, H. (1953). The interpersonal theory of psychiatry. New York: Norton.

Tronick, E. Z. (1989). Emotions and emotional communication in infants. American Psychologist, 44, 112-119.

Truax, C., \& Carkhuff, R. (1967). Toward effective counseling and psychotherapy: Training and practice. Chicago: Aldine.

Winnicott, D. W. (1963). Psychiatric disorders in terms of infantile maturational processes. In The maturational process and the facilitating environment (pp. 230-241). New York: International Universities Press.

Wolf, E. (1988). Treating the self: Elements of clinical self psychology. New York: Guilford.

Zetzel, E. (1956). Current concepts of transference. International Journal of Psychoanalysis, 37, 369-376.

Zetzel, E. (1970). The capacity for emotional growth. New York: International Universities Press.

Jerrold R. Brandell, PhD, CSW, BCD, is professor and chairperson, graduate concentration in interpersonal practice, Wayne State University School of Social Work. Shoshana Ringel, PhD, LCSW-C, is Assistant Professor, the University of Maryland, Baltimore School of Social Work. Drs. Brandell and Ringel are currently collaborating on a book on attachment theory in dynamic social work practice. Correspondence regarding this article may be sent to the first author at jrbrandell@wayne.edu or Wayne State University, 4756 Cass Avenue, Detroit, MI 48202.

Author's note. Portions of this article, though in revised form, appear in Jerrold R. Brandell's forthcoming book, Psychodynamic Social Work (Columbia University Press, 2004).

Manuscript received: May 16, 2003

Revised: January 8, 2004

Accepted: March 9, 2004 